\title{
EXPORTAÇÃO DE NUTRIENTES MINERAIS POR FRUTOS DE ACEROLEIRA COLHIDOS EM DIFERENTES ÉPOCAS DO ANO ${ }^{1}$
}

\author{
ROSIANE DE LOURDES SILVADE LIMA ${ }^{2}$, GILVAN BARBOSAFERREIRA ${ }^{3}$, JAIRO OSVALDOCAZETTA $^{4}$, \\ OLMAR BALLER WEBER ${ }^{5}$, DALMO LOPES DE SIQUEIRA ${ }^{6}$, JOÃO RODRIGUES DE PAIVA ${ }^{5}$
}

RESUMO - A aceroleira produz, no Nordeste brasileiro, de quatro a seis safras por ano e é de se esperar que as exportações de elementos minerais variem em função das diferentes épocas de colheita e das progênies, entre outros fatores. Nesse contexto, este trabalho foi conduzido no Campo Experimental da Embrapa Agroindústria Tropical, em Pacajus-CE (4¹0' S; 38 $27^{\prime}$ 'W), no ano agrícola de 1999/2000, com o objetivo de determinar a exportação de N, P, K, Ca, Mg, S, Cu, Fe, Mn e Zn por tonelada de fruta fresca, em diferentes progênies e épocas de colheita. Avaliaram-se os frutos de seis progênies (plantas com 2,5 anos de idade e produção média de 18,16 a 27,62 kg/planta/ano, cultivadas em sistema de sequeiro), em seis épocas de colheita. Adotou-se o delineamento em blocos casualizados, em esquema de parcelas subdivididas no tempo (considerando as progênies como parcelas e as épocas de avaliação as subparcelas), com 4 repetições. Verificou-se que a maior exportação de nutrientes ocorreu nos meses de maior precipitação (fevereiro a abril); as progênies não diferiram entre si quanto à exportação de macronutrientes; as progênies P-52, P- 93 e P-97 exportaram maior quantidade de $\mathrm{Cu}$ e $\mathrm{Zn}$; a sequiência de exportação de nutrientes por tonelada de frutos frescos de aceroleira foi: $\mathrm{K}>\mathrm{N}>\mathrm{P}>\mathrm{Mg}>\mathrm{Ca}>\mathrm{S}>\mathrm{Fe}>\mathrm{Zn}>\mathrm{Mn}>\mathrm{Cu}$.

Termos para indexação: Malpighia emarginata, épocas de colheita, progênies.

\section{EXPORTATION OF MINERAL NUTRIENTS BY WEST INDIAN CHERRY FRUITS HARVESTED IN DIFFERENT SEASONS}

ABSTRACT- The fruits of West Indian cherry plants are harvested on four to six times along the year in the Brazilian northeast region. It is expected that exportation of mineral elements by fruits may vary among genotypes and harvest times. Thus, this work was carried out at the experimental field of Embrapa Tropical Agroindustry, located in Pacajus, CE (4¹0’ S; 38²7’ W), Brazil, in 1999/2000 cycle, aiming to determine the exportation of $\mathrm{N}, \mathrm{P}, \mathrm{K}, \mathrm{Ca}, \mathrm{Mg}, \mathrm{S}, \mathrm{Cu}, \mathrm{Fe}, \mathrm{Mn}$ and $\mathrm{Zn}$ per ton of fresh fruit from six genotypes, in six harvest times. The plants were with 2.5 years old, and yield average from 18.16 to $27.62 \mathrm{~kg} / \mathrm{plant} / \mathrm{year}$, cultured under natural weather conditions (without irrigation). It was used a complete randomized block design, with split plots (genotypes in plots, and harvest times as sub-plots) with four replications. It was observed that the nutrient exportation was greater in the season with the most volume of rain (from February to April); genotypes do not induce important difference on macronutrients exportations; genotypes P52, P- 93 e P-97 exported greater amounts of $\mathrm{Cu}$ and $\mathrm{Zn}$; and the exportation sequence of nutrients was: $\mathrm{K}>\mathrm{N}>\mathrm{P}>\mathrm{Mg}>\mathrm{Ca}>\mathrm{S}>\mathrm{Fe}>\mathrm{Zn}>\mathrm{Mn}>\mathrm{Cu}$.

Index Terms: Malpighia emarginata, harvest seasons, genotypes.

\section{INTRODUÇÃO}

A aceroleira é uma planta de crescimento intenso, de alta demanda por nutrientes quando cultivada em condições de clima e manejo adequados. As plantas iniciam a produção já a partir do primeiro ano de cultivo, ocasião em que podem produzir até $2 \mathrm{~kg}$ de frutos frescos. Aos seis anos, produzem, em média, $47 \mathrm{~kg}$ por planta (Braga Sobrinho et al., 2001). Entretanto, há registros de até 179,2 kg planta ano (Gonzaga Neto et al., 1999).

Segundo Andrade (2004), a determinação das quantidades dos nutrientes exportados pelos frutos é importante para o cálculo de reposição com adubos, de modo a garantir o aumento ou manutenção da produtividade com frutos de qualidade. Por isso, essas informações ajudam a compor o cenário para se planejar um manejo da cultura de forma a manter equilibrada a fertilidade do solo e a garantir a produtividade e a rentabilidade.

É de se esperar que as aceroleiras exportem, pelos frutos, quantidades variáveis de nutrientes, dependendo da variedade, produção, do ambiente e do manejo da cultura. Alguns desses aspectos têm sido estudados. Cunha et al. (1993) relataram que a exportação de nitrogênio $(\mathrm{N})$, fósforo $(\mathrm{P})$ e potássio $(\mathrm{K})$ em frutas frescas era de 2.554; $361 \mathrm{e} 2.975 \mathrm{~g} \mathrm{t}^{-1}$, respectivamente. Alves et

${ }^{1}$ (Trabalho 190-07). Recebido em: 03-08-2007. Aceito para publicação em:03-07-2008.

${ }^{2} \mathrm{Eng}^{\mathrm{a}} \mathrm{Ag}^{\mathrm{o}}$, Doutoranda em Agronomia (Produção Vegetal), Unesp-Jaboticabal. E-mail: limarosiane@ yahoo.com.br

${ }^{3}$ Eng $^{\circ}$ Ag $^{\circ}$ D.Sc., Embrapa Roraima BR 174, km 08, Distrito Industrial, C.Postal 133, Boa Vista/Roraima, CEP 69301-970. E-mail: gilvan@cpafrr.embrapa.br ${ }^{4} \mathrm{Eng}^{\mathrm{O}} \mathrm{Ag}^{\mathrm{O}}$ D.Sc, Prof. Adjunto, Unesp - Universidade Estadual Paulista -Jaboticabal-SP:E-mail: cazetta@ fcav.unesp.br

${ }^{5} \mathrm{Eng}^{\circ} \mathrm{Ag}^{\circ}$ D.Sc., Embrapa Agroindústria Tropical, Av. Dra. Sara Mesquita, 2270. Pici, Fortaleza-CE, 60511-110. E-mail: weber@cnpat.embrapa.br; paiva@ cnpat.embrapa.br.

${ }^{6} \mathrm{Eng}^{\circ} \mathrm{Ag}^{\mathrm{o}}$ D.Sc, Prof. Adjunto, Universidade Federal de Viçosa, Deptos. de Fitotecnia, 36571-000, Viçosa-MG. E-mail: siqueira@ufv.br.

Rev. Bras. Frutic., Jaboticabal - SP, v. 30, n. 3, p. 806-811, Setembro 2008 
al. (1990) detectaram $1.747 \mathrm{~g}$ de N, $271 \mathrm{~g}$ de P e $2.559 \mathrm{~g}$ de K por tonelada da fruta. Valores próximos a estes foram detectados também por Freire (1995), sendo $1.132 \mathrm{~g} \mathrm{t}^{-1} \mathrm{de} \mathrm{N}, 175 \mathrm{~g} \mathrm{t}^{-1} \mathrm{de} \mathrm{Pe}$ $1.701 \mathrm{~g} \mathrm{t}^{-1} \mathrm{de} \mathrm{K}$. Andrade (2004) determinou que, em geral, são necessários 1,7-1,8 $\mathrm{kg}$ de N, 0,3 kg de P, 2,6-2,7 kg de K, 0,5 kg $\mathrm{de} \mathrm{Ca}, 0,14 \mathrm{~kg}$ de $\mathrm{Mg}, 0,2 \mathrm{~kg}$ de S, 1,62 g de Cu, 9,91 g de Fe, 1,69 $\mathrm{g}$ de $\mathrm{Mn}$ e 2,30 $\mathrm{g}$ de $\mathrm{Zn}$ para produzir uma tonelada de frutas frescas da aceroleira. Em outro estudo com aceroleiras cultivadas em seis diferentes municípios do Estado da Paraíba, Freire et al. (2007) observaram que os teores médios de $\mathrm{P}$ foram similares para as plantas dos diferentes pomares e que, também, independentemente do local, a exportação de nutrientes pela colheita dos frutos obedeceu à seguinte ordem decrescente: K> $\mathrm{N}>$ P. Brunini et al. (2004) detectaram diferenças significativas para os teores de $\mathrm{P}, \mathrm{K}, \mathrm{Ca}, \mathrm{Mg}, \mathrm{S}, \mathrm{Cu}, \mathrm{Fe}, \mathrm{Mn}$ e $\mathrm{Zn}$ na polpa de frutos de acerola colhidos em diferentes pomares cultivados em distintas regiões do Estado de São Paulo e verificaram maiores variações para os teores de $\mathrm{Ca}, \mathrm{Cu}$ e $\mathrm{Zn}$. De acordo com os autores, essa variação pode estar relacionada ao local de origem e à nutrição do solo. Além dos estudos sobre as progênies, inexistem informações sobre a influência de épocas de colheita na nutrição da cultura, principalmente com respeito aos novos clones lançados pelo melhoramento genético.

Diante desse contexto, este estudo teve o objetivo de avaliar a variação sazonal dos teores de $\mathrm{N}, \mathrm{P}, \mathrm{K}, \mathrm{Ca}, \mathrm{Mg}, \mathrm{S}, \mathrm{Cu}$, $\mathrm{Fe}, \mathrm{Mn}$ e $\mathrm{Zn}$ em frutos obtidos de diferentes progênies de aceroleira e a sequiência de exportação de nutrientes minerais pela colheita das frutas frescas.

\section{MATERIAL E MÉTODOS}

O ensaio foi conduzido na coleção de progênies de aceroleira da Embrapa Agroindústria Tropical, em Pacajus-CE, distante $55 \mathrm{~km}$ de Fortaleza-CE, no período de dezembro de 1999 a outubro de 2000 . As coordenadas geográficas do local são $4^{\circ} 10^{\prime} \mathrm{S}$ e $38^{\circ} 27^{\prime} \mathrm{W}$, altitude de $60 \mathrm{~m}$ acima do nível do mar. O clima na região, de acordo com a classificação de Köppen, é Aw. A precipitação pluvial média é de $1.100 \mathrm{~mm} / \mathrm{ano}$, com regime caracterizado por chuvas de verão/outono.

Adotou-se o delineamento de blocos ao acaso, com quatro repetições, e os tratamentos foram arranjados em esquema de parcelas subdivididas no tempo, estando nas parcelas as seis progênies de aceroleira (P-52, P-66, P-78, P-91, P-93 e P-97) e, nas subparcelas, as seis épocas de avaliação (meses do ano agrícola 1999/2000: dezembro de 1999, fevereiro, abril, junho, agosto e outubro/2000). Cada parcela foi formada por quatro plantas.

O solo da área experimental foi classificado como Podzólico Vermelho-Amarelo Tb eutrófico, A fraco, com textura arenosa/média, ou Neossolo Regolítico (Regossolo) textura areia franca, de acordo com a nova classificação. Apresenta $\mathrm{pH} 4,8$; $1,0 \mathrm{mmol}_{\mathrm{c}} \mathrm{dm}^{-3} \mathrm{de} \mathrm{Al}$ trocável; $57 \%$ de saturação por bases; 2,21

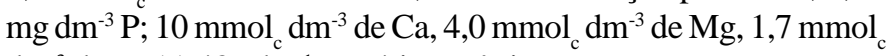
$\mathrm{dm}^{-3} \mathrm{de} \mathrm{K}, 11,48 \mathrm{~g} \mathrm{~kg}^{-1}$ matéria orgânica.

As médias mensais de precipitação pluvial e temperaturas máximas e mínimas no local do experimento estão expostas na
Figura 1, onde se pode observar que, entre os meses de dezembro de 1999 e outubro de 2000, foram registrados $1.122 \mathrm{~mm}$ de chuva, sendo tal perfil pluviométrico considerado satisfatório para o desenvolvimento da cultura.

As plantas de todas as progênies tinham idade de 2,5 anos, cultivadas em regime de sequeiro, no espaçamento $3 \times 4 \mathrm{~m}$, apresentando as seguintes produções médias de frutos frescos: $\mathrm{P}-52=18,16 ; \mathrm{P}-66=27,62 ; \mathrm{P}-78=23,99 ; \mathrm{P}-91=26,91 ; \mathrm{P}-93=19$, 65 e P-97 $=23$, 38, com os valores expressos em kg/planta/ano.

A adubação consistiu na aplicação de $30 \mathrm{~g}$ de uréia, $50 \mathrm{~g}$ de monoamoniofosfato (MAP), $20 \mathrm{~g}$ de sulfato de magnésio e 40 $\mathrm{g}$ de cloreto de potássio por planta. A aplicação foi em pequenos sulcos, abertos em forma de meia-lua na projeção da copa, realizada mensalmente, no período de dezembro de 1999 a outubro de 2000, correspondendo a um total de 185; 250; 240; 20 e $28 \mathrm{~kg}$ ha $^{-1}$ de $\mathrm{N} ; \mathrm{P}_{2} \mathrm{O}_{5} ; \mathrm{K}_{2} \mathrm{O} ; \mathrm{Mg}$ e S, respectivamente.

Para a determinação dos teores de nutrientes nos frutos e posterior cálculo das quantidades de macro e micronutrientes exportados, coletaram-se 50 frutos frescos por parcela e, imediatamente após, lavagem com água deionizada, secos em estufa de circulação de ar forçada, até peso constante. As amostras secas foram trituradas em moinho tipo Willey, passadas em peneira com malhas de 20 mesh e submetidas às análises químicas. Uma porção das amostras trituradas foi submetida à digestão nítrico-perclórica para a determinação das concentrações de $\mathrm{P}, \mathrm{K}, \mathrm{Ca}, \mathrm{Mg}, \mathrm{S}, \mathrm{Cu}, \mathrm{Fe}, \mathrm{Mn}$ e $\mathrm{Zn}$, enquanto outra foi submetida à digestão sulfúrica para a determinação do teor de $\mathrm{N}$. O N foi quantificado pelo método colorimétrico de Nessler; o P, pelo método do fosfomolibdato, e a redução, pela vitamina C, modificado por Braga e Defelipo (1974); o K, por fotometria de chama; o $\mathrm{S}$, por turbidimetria do sulfato de bário (Blanchar et al., 1963), e os demais (Ca, Mg, Cu, Fe, Mn e Zn) foram quantificados por espectrofotometria de absorção atômica em chama.

Calculou-se a quantidade de nutrientes exportada por tonelada de frutos frescos, a partir do teor do nutriente encontrado na matéria seca.

Os valores obtidos foram submetidos à análise de variância (teste $\mathrm{F}$ ), e as médias dos fatores, comparadas pelo teste de Tukey $(5 \%)$.

\section{RESULTADOS E DISCUSSÃO}

As quantidades de N, P, K, Ca, S, Fe e Mn exportadas com as frutas variaram dentre as épocas de colheita, enquanto as quantidades de $\mathrm{Mg}$ variaram tanto dentro das progênies como entre algumas épocas estudadas (Tabelas 1 e 2). A exportação de $\mathrm{N}$ foi maior em fevereiro/2000, alcançando valores médios de $3,10 \mathrm{~kg} \mathrm{t}^{-1}$. Esses resultados concordam com os obtidos por Cunha et al. (1993), que também realizaram estudos com aceroleiras cultivadas em regime de sequeiro, em condições edafoclimáticas bastante semelhantes às do presente estudo. Por outro lado, os valores obtidos neste trabalho são superiores aos observados por Alves et al. (1990) e Freire (1995). No caso de Alves et al. (1990), as plantas foram cultivadas em condições similares às deste trabalho, porém estudando plantas um pouco mais jovens 
(2 anos de idade) e, no caso da pesquisa de Freire (1995), os frutos tinham sido colhidos de aceroleiras cultivadas em diferentes localidades do Estado da Paraíba que, apesar de ter características edafoclimáticas médias parecidas com as de Pacajus-CE, a distribuição das chuvas e a adubação foram diferentes da utilizada no presente estudo, o que justifica as diferenças nos valores absolutos quando confrontados aos deste trabalho.

Observaram-se valores intermediários na exportação de $\mathrm{N}$ de abril a agosto de 2000 (entre 2,06 e 2,30 $\mathrm{kg} \mathrm{t}^{-1}$ ), e o menor valor, em outubro $\left(1,73 \mathrm{~kg} \mathrm{t}^{-1}\right)$. A média de exportação de $\mathrm{N}$ foi de $2,27 \mathrm{~kg} \mathrm{t}^{-1}$, sendo de $85,0 \mathrm{~kg} \mathrm{ha}^{-1}$ ano $^{-1} \mathrm{de} \mathrm{N}$, para uma produtividade média de $37,49 \mathrm{tha}^{-1}$ de frutas frescas ou $45 \mathrm{~kg}$ planta $^{-1}$, indicando que, do $\mathrm{N}$ aplicado na adubação, $46 \%$ foi exportado pelos frutos. A quantidade de $\mathrm{N}$ exportada nesta pesquisa foi superior aos resultados encontrados por Andrade (2004), que estão na faixa de $1,7-1,8 \mathrm{~kg} \mathrm{t}^{-1}$ de fruta fresca colhida. Deve ser ressaltado que as informações descritas por Andrade (2004) são bastante gerais e referem-se a dados e recomendações para as condições de cerrado, que são bastante distintas daquelas de Pacjus-CE, em que as plantas do presente estudo foram cultivadas, o que provavelmente levou a valores diferentes.

As quantidades de $\mathrm{P}$ exportadas variaram dentro das épocas de amostragem, que foram maiores em fevereiro/2000, alcançando $0,29 \mathrm{~kg} \mathrm{t}^{-1}$ com média de $0,27 \mathrm{~kg} \mathrm{t}^{-1}$ (Tabela 1). A exportação decresceu em agosto $\left(0,25 \mathrm{~kg} \mathrm{t}^{-1} \mathrm{de}\right.$ frutos frescos), semelhantemente ao observado para o N. Esses resultados para o P encontram-se abaixo de $0,36 \mathrm{~kg} \mathrm{t}^{-1}$ observado por Cunha et al. (1993) e superiores aos $0,17 \mathrm{~kg} \mathrm{t}^{-1}$ obtidos por Freire (1995). Por outro lado, são concordantes com o de $0,27 \mathrm{~kg} \mathrm{t}^{-1}$ encontrado por Alves et al. (1990) e $0,3 \mathrm{~kg} \mathrm{t}^{-1}$ observado por Andrade (2004). A exportação total foi de $10,1 \mathrm{~kg} \mathrm{ha}^{-1}$ ano $^{-1}$ de $\mathrm{P}$ ou $23,3 \mathrm{~kg} \mathrm{ha}^{-1}$ ano ${ }^{-1}$ de $\mathrm{P}_{2} \mathrm{O}_{5}$ ou seja, 9,3\% do fósforo aplicado na adubação foram exportados nos frutos colhidos. Levando em conta que as condições de Alves et al. (1990) eram semelhantes à deste trabalho e que a dos demais autores eram distintas, considera-se que os dados do presente trabalho correspondem a valores intermediários, sendo praticamente a média calculada usando o maior e o menor valor descrito nas referências de literatura acima citadas.

Para K, a maior quantidade exportada $\left(2,71 \mathrm{~kg} \mathrm{t}^{-1}\right)$ ocorreu em fevereiro (Tabela 1). Este período (começo das chuvas) coincide com a fase de emergência e crescimento de brotos com pequena produção de frutos (Cordeiro, 2000). Possivelmente, por esta ocasião, a planta está carreando nutrientes mais intensamente para o enchimento dos frutos e manutenção da pequena florada em desenvolvimento e, por isso, a quantidade total de frutos é ainda pequena para diluir os nutrientes redistribuídos, mantendo elevada a concentração dos mesmos.

$\mathrm{O} \mathrm{K}$ foi o nutriente mais exportado, seguido do $\mathrm{N}$, mantendo valores médios de 2,29 kg/t. Cunha et al. (1993) mencionam que são exportados aproximadamente $2,97 \mathrm{~kg}$ de $\mathrm{K}$ por tonelada de fruta fresca de acerola, enquanto Alves et al. (1990) e Freire (1995) relatam uma exportação média de 2,55 e 1,70 $\mathrm{kg} \mathrm{t}^{-1}$ de $\mathrm{K}$, respectivamente. As quantidades de $\mathrm{K}$ exportadas pela aceroleira nesta pesquisa foram concordantes com as obtidas por Alves et al. (1990), e as justificativas são as mesmas apresentadas acima, na discussão dos resultados do $\mathrm{N}$ e do P. A extração total pelos frutos foi de $85,9 \mathrm{~kg} \mathrm{ha}^{-1} \mathrm{ano}^{-1}$ de K ou 103,0 $\mathrm{kg} \mathrm{ha}^{-1}$ ano $^{-1}$ de $\mathrm{K}_{2} \mathrm{O}$. Isto corresponde a $42,9 \%$ do potássio aplicado na adubação anual usada, caracterizando uma grande demanda dos frutos por este nutriente.

As quantidades de $\mathrm{Ca}$ exportadas variaram dentro das épocas de amostragem, sendo maiores em abril e junho, chegando a $0,18 \mathrm{~kg} \mathrm{t}^{-1}$ (Tabela 1). As exportações decresceram em agosto $\left(0,15 \mathrm{~kg} \mathrm{t}^{-1}\right)$, chegando a outubro com valor mínimo de $0,14 \mathrm{~kg} \mathrm{t}^{-}$ 1 . Neste estudo, as quantidades médias de $\mathrm{Ca}$ exportadas foram de $0,16 \mathrm{~kg} \mathrm{t}^{-1}$. Semelhantemente ao observado com o N, P e K, as quantidades de $\mathrm{Ca}$ exportadas por tonelada de frutos frescos diminuíram no segundo semestre do ano estudado. A exportação média total foi de $6,12 \mathrm{~kg} \mathrm{ha}^{-1} \mathrm{ano}^{-1} \mathrm{de} \mathrm{Ca}$.

Quanto ao $\mathrm{Mg}$, observaram-se efeitos independentes de épocas (Tabela 1) e de progênies (Tabela 2). $\mathrm{O} \mathrm{Mg}$ apresentou valor mínimo de $0,16 \mathrm{~kg} \mathrm{t}^{-1}$ na amostragem de agosto e máximo de $0,23 \mathrm{~kg} \mathrm{t}^{-1}$ na de abril. Dentre os clones estudados, o P-52 apresentou maior exportação do nutriente, alcançando $0,23 \mathrm{~kg} \mathrm{t}$ ${ }^{1}$ de fruta fresca colhida, enquanto a P-91 mostrou menor exportação de $\mathrm{Mg}$, com valor médio de $0,18 \mathrm{~kg} \mathrm{t}^{-1}$. As quantidades de $\mathrm{Mg}$ exportadas pela aceroleira foram superiores às encontradas por Andrade (2004), que cita quantidades de 0,14 $\mathrm{kg}$ de $\mathrm{Mg}$ por tonelada de fruta fresca colhida. Os dados desta pesquisa indicaram maiores teores de $\mathrm{Mg}$ no período chuvoso, quando fortes crescimentos vegetativos e produtivos ocorrem. Fazendo-se um balanço para este nutriente, observa-se que houve exportação média de $0,20 \mathrm{~kg} \mathrm{t}^{-1}$ (Tabela 1) e total de 7,62 $\mathrm{kg} \mathrm{ha}^{-1} \mathrm{de}$ $\mathrm{Mg}$ ou, ainda, 12,7 $\mathrm{kg} \mathrm{ha}^{-1}$ de $\mathrm{MgO}$, o que corresponde à exportação de $63,5 \%$ do $\mathrm{Mg}$ adicionado na adubação.

As quantidades exportadas de enxofre foram bastante baixas, variando de 0,04 a $0,08 \mathrm{~kg} \mathrm{t}^{-1}$, com média de $0,06 \mathrm{~kg} \mathrm{t}^{-1}$ (Tabela 1). Como o fruto da acerola é suculento, rico em água e sais minerais e pobres em proteínas, esses resultados eram previstos. Em frutos secos, Andrade (2004) encontrou valores de $0,2 \mathrm{~kg} \mathrm{t}^{-1} \mathrm{o}$ que, levando em conta o teor de água dos frutos, corresponderia a valores parecidos com os obtidos no presente estudo.

Quanto ao ferro, ocorreram intensas variações entre as épocas de amostragem (Tabela 1). As quantidades desse nutriente foram superiores em abril, alcançando teores médios de $67,52 \mathrm{~g} \mathrm{t}^{-1}$ para todas as progênies; as exportações decresceram de abril a junho, em média de $50 \%$, aumentando em agosto e diminuindo bruscamente em outubro, quando atingiram o valor mínimo de 25,49 $\mathrm{g} \mathrm{t}^{-1}$. Os períodos de aumento (dezembro e abril) e diminuição (junho e outubro) (Tabela1) não coincidiram com as flutuações dos valores observados para o $\mathrm{P}$ e K, porém similares aos do $\mathrm{N}$ em outubro. Apesar disto, a tendência de maior exportação no primeiro semestre também foi observada, como nos demais nutrientes analisados. De acordo com Andrade (2004), o Fe é o principal micronutriente exportado pela aceroleira, atingindo $9,91 \mathrm{~g} \mathrm{t}^{-1}$. A mesma tendência foi observada neste trabalho, porém com um valor de 4,3 vezes maior que o citado pelo último autor citado $\left(41,35 \mathrm{~g} \mathrm{t}^{-1}\right)$.

Quanto ao Mn, observou-se que a maior exportação deste 
nutriente ocorreu em abril (Tabela 1), similar ao Fe. Observaramse variações significativas para $\mathrm{Mn}$ em diferentes períodos do ano, com o valor máximo observado em abril $\left(18,43 \mathrm{~g} \mathrm{t}^{-1}\right)$, os mínimos de junho a outubro (entre 8,27 e $9,70 \mathrm{~g} \mathrm{t}^{-1}$ ) e os intermediários em dezembro e fevereiro $\left(12,99\right.$ e 13,93 $\mathrm{g} \mathrm{t}^{-1}$, respectivamente). Segundo Andrade (2004), o Mn ocupa a terceira posição entre os micronutrientes exportados pela aceroleira, sendo retirado $1,69 \mathrm{~g} \mathrm{t}^{-1}$ deste elemento nas frutas frescas. Porém, tal valor é cerca de 7 vezes menor que o observado no presente trabalho $(12,04)$ e indica uma intensa variação dos teores acumulados no fruto, em conseqüência da mudança do genótipo, solo, adubação e manejo aplicado na cultura.

As quantidades de $\mathrm{Cu}$ exportadas variaram mais entre progênies do que entre as épocas de amostragem (Tabela 2). De forma geral, os valores exportados ficaram entre 10,1 e 4,4 $\mathrm{g} \mathrm{t}^{-1}$, sendo o maior observado em abril, os menores no período de junho a outubro e o intermediário em dezembro. Andrade (2004) encontrou uma exportação de apenas $1,62 \mathrm{~g} \mathrm{t}^{-1}$ de cobre pelos frutos frescos da aceroleira, que é um valor proporcionalmente bem inferior aos encontrados no presente estudo, lembrando que tal autor se refere a condições de cerrado e, portanto, condição edafoclimática distinta.

Para os dados sobre o $\mathrm{Zn}$, observa-se que as variações foram mais dependentes da época de colheita do que das progênies (Tabela 3), com maior acúmulo do nutriente nos frutos colhidos em fevereiro de 2000, seguindo praticamente a mesma tendência apresentada pelo $\mathrm{Cu}$. As quantidades de $\mathrm{Zn}$ exportadas variaram entre 9,6 $\mathrm{g} \mathrm{t}^{-1}$, valor observado para P-93 na amostragem de junho/2000, e a $36 \mathrm{~g} \mathrm{t}^{-1}$ obtido para a P-97 na amostragem de outubro/2000. A grande variabilidade dos dados obtidos para este nutriente $(\mathrm{CV}=41,55 \%)$ não permitiu uma análise muito precisa entre as diferentes progênies. Em geral, pode-se verificar que as progênies P-66, P-52 e P-97 tiveram maior exportação de $\mathrm{Cu}$, e as progênies P-97, P-52 e P-93 tiveram maior exportação de Zn
(Tabelas 2 e 3). Na média de todas as progênies e épocas, observou-se acúmulo de $\mathrm{Zn}$ de 16,36 $\mathrm{g} \mathrm{t}^{-1}$ de frutos frescos, o que corresponde a uma exportação total de $613,34 \mathrm{~g} \mathrm{ha}^{-1} \mathrm{ano}^{-1}$. Assim sendo, depois do $\mathrm{Fe}$, o $\mathrm{Zn}$ é o micronutriente mais exportado por frutos de aceroleira, concordando com as informações de Andrade (2004).

De forma geral, no presente trabalho, observou-se que a exportação de nutrientes pelos frutos variou pouco entre as diferentes progênies estudadas, e é interessante observar que poucas diferenças também foram encontradas por Freire et al. (2007), quando cultivaram aceroleiras em distintos municípios do Estado da Paraíba, ou seja, em distintos solos, mas dentro de uma mesma região climática. Brunini et al. (2004), por outro lado, observaram algumas variações significativas quando analisaram frutos colhidos de diferentes regiões do Estado de São Paulo, embora os teores dos nutrientes tenham permanecido dentro de faixas bastante estreitas, o que reforça a observação deste estudo de que a exportação de nutrientes por tonelada de frutos frescos varia mais em função das condições de cultivo do que das diferenças genéticas das plantas.

Pelos dados do presente trabalho, nota-se que, além da adubação realizada com base na análise do solo para o ajuste das variáveis de fertilidade, as adubações de manutenção dos pomares de aceroleiras devem ser realizadas com fórmulas que consideram as exportações pelas colheitas dos frutos, ou seja: $\mathrm{K}>\mathrm{N}>\mathrm{P}$ e com valores estimados com base na expectativa de colheita em cada período do ano. Sabendo que, na época das águas de cada região (janeiro a julho, no caso de Pacajus-CE, Figura 1), é quando os solos podem sofrer as maiores perdas dos nutrientes mais solúveis e dinâmicos, como, por exemplo, o $\mathrm{N}$ e o $\mathrm{K}$, as adubações devem ser parceladas, e cada adubação parcial, por sua vez, deve suprir as quantidades de nutrientes que serão utilizadas e extraídas pelos frutos no período entre esta e a próxima adubação parcial.

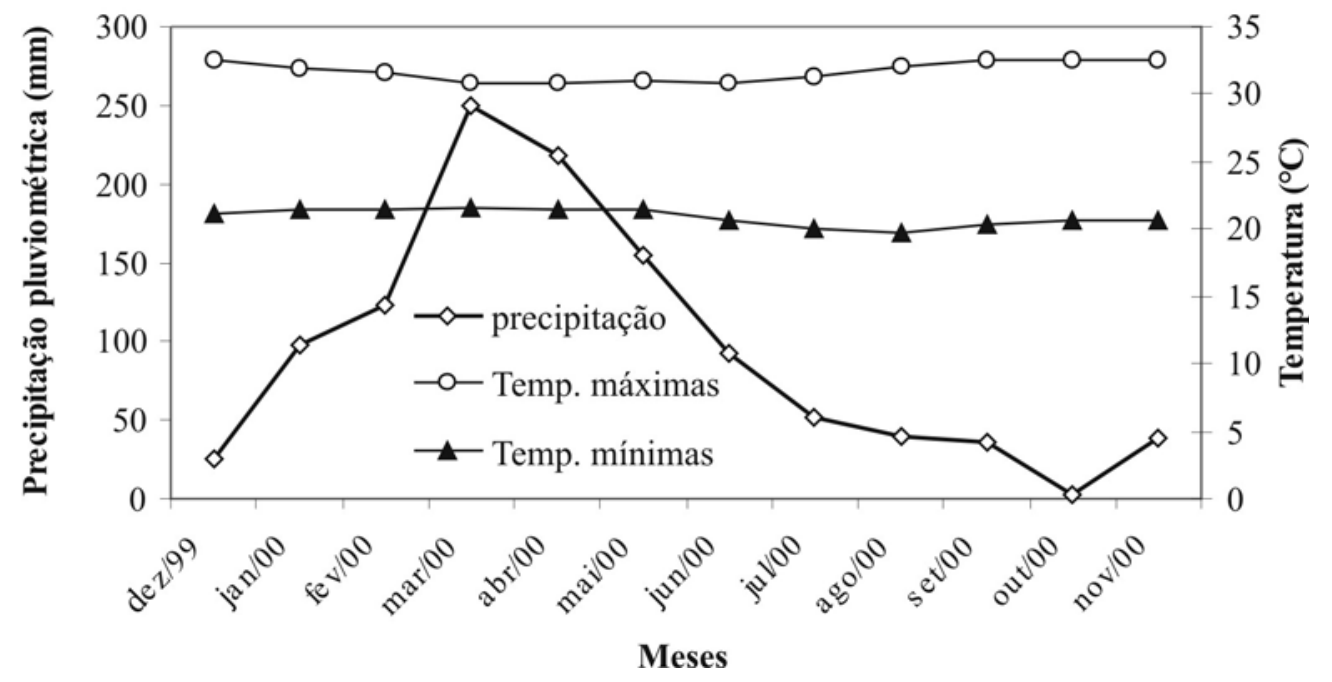

FIGURA 1 - Médias mensais de precipitação pluviométrica e temperaturas máximas e mínimas em Pacajus-CE. 
TABELA 1 - Quantidade de N, P, K, Ca, Mg, S, Fe e Mn exportadas por tonelada de frutos frescos de aceroleira em diferentes épocas do ano (meses do ano agrícola de 1999/2000). Pacajus-CE, 2000.

\begin{tabular}{|c|c|c|c|c|c|c|c|c|}
\hline Época & $\mathrm{N}$ & $P$ & $\mathrm{~K}$ & $\mathrm{Ca}$ & $\mathrm{Mg}$ & $\mathrm{S}$ & $\mathrm{Fe}$ & $\mathrm{Mn}$ \\
\hline & \multicolumn{6}{|c|}{ 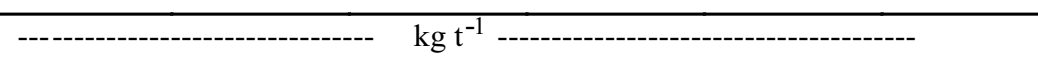 } & \multicolumn{2}{|c|}{-------- - $\mathrm{g} \mathrm{t}^{-1}$------ } \\
\hline Dez & $2,22 \mathrm{~b}$ & $0,27 \mathrm{ab}$ & $2,37 \mathrm{~b}$ & $0,16 \mathrm{abc}$ & $0,21 \mathrm{ab}$ & $0,06 \mathrm{bc}$ & $44,85 \mathrm{~b}$ & $12,99 \mathrm{~b}$ \\
\hline Fev & $3,10 \mathrm{a}$ & $0,29 \mathrm{a}$ & $2,71 \mathrm{a}$ & $0,17 \mathrm{abc}$ & 0,19 bc & $0,07 \mathrm{ab}$ & $39,94 \mathrm{~b}$ & $13,43 \mathrm{~b}$ \\
\hline Abr & $2,06 \mathrm{bc}$ & $0,27 \mathrm{ab}$ & $2,38 \mathrm{~b}$ & $0,18 \mathrm{a}$ & $0,23 \mathrm{a}$ & $0,04 \quad \mathrm{~d}$ & $67,52 \mathrm{a}$ & $18,43 \mathrm{a}$ \\
\hline Jun & $2,20 \mathrm{~b}$ & $0,27 \mathrm{ab}$ & $2,08 \quad \mathrm{c}$ & $0,18 \mathrm{a}$ & $0,21 \mathrm{ab}$ & $0,07 \mathrm{abc}$ & $30,71 \mathrm{~b}$ & 9,44 \\
\hline Ago & $2,30 \mathrm{~b}$ & $0,25 \mathrm{~b}$ & $1,97 \mathrm{c}$ & 0,15 bc & $0,16 \mathrm{c}$ & $0,05 \mathrm{~cd}$ & $39,57 \mathrm{~b}$ & 8,27 \\
\hline Out & $1,73 \mathrm{c}$ & $0,27 \mathrm{ab}$ & $2,25 \mathrm{bc}$ & $0,14 \quad \mathrm{c}$ & $0,22 \mathrm{a}$ & $0,08 \mathrm{a}$ & $25,49 \mathrm{~b}$ & 9,70 \\
\hline Média & 2,27 & 0,27 & 2,29 & 0,16 & 0,20 & 0,06 & 41,35 & 12,04 \\
\hline CV (\%) & $22,7 \mathrm{~b}$ & 11,8 & 14,5 & 21,0 & 17,8 & 33,0 & 62,0 & 27,2 \\
\hline
\end{tabular}

Médias de épocas seguidas das mesmas letras, minúsculas na coluna, não diferem entre si, pelo teste de Tukey (p $<0,05)$.

TABELA 2 - Quantidade de Cu e Mg exportada por tonelada de frutos frescos de progênies de aceroleira em diferentes épocas do ano (meses do ano agrícola de 1999/2000). Pacajus-CE, 2000.

\begin{tabular}{|c|c|c|c|c|c|c|c|}
\hline \multirow{2}{*}{ Progênies } & \multicolumn{6}{|c|}{$\mathrm{Cu}\left(\mathrm{g} \mathrm{t}^{-1}\right)$} & \multirow[t]{2}{*}{$\operatorname{Mg}\left(\mathrm{kg} \mathrm{t}^{-1}\right)$} \\
\hline & Dezembro & Fevereiro & Abril & Junho & Agosto & Outubro & \\
\hline$P-52$ & 6,5 Aa & 8,3 Aa & 8,6 Aa & 8,0 Aa & 7,3 Aa & $6,8 \mathrm{Aa}$ & $0,23 \mathrm{a}$ \\
\hline$P-66$ & $10,1 \mathrm{Aa}$ & $8,5 \mathrm{AB}$ a & $6,6 \mathrm{Ba}$ & $8,0 \mathrm{AB} \mathrm{a}$ & $6,9 \mathrm{~B} \mathrm{a}$ & $6,5 \mathrm{Ba}$ & $0,21 \mathrm{ab}$ \\
\hline P-78 & 6,6 Aa & 7,6 Aa & $5,4 \mathrm{Aa}$ & $5,2 \mathrm{Aa}$ & $5,5 \mathrm{Aa}$ & $6,1 \mathrm{Aa}$ & $0,19 \mathrm{~b}$ \\
\hline P-91 & $7,0 \quad \mathrm{AB}$ a & $9,0 \mathrm{Aa}$ & $6,3 \mathrm{AB}$ a & $6,0 \mathrm{~B} \mathrm{a}$ & $6,3 \mathrm{Aba}$ & $7,5 \mathrm{AB} \mathrm{a}$ & $0,18 \quad b$ \\
\hline P-93 & $5,9 \mathrm{Aa}$ & $5,7 \mathrm{Aa}$ & $4,4 \mathrm{Aa}$ & $5,0 \mathrm{Aa}$ & $6,0 \mathrm{Aa}$ & $6,2 \mathrm{Aa}$ & $0,20 \mathrm{ab}$ \\
\hline P-97 & $7,2 \mathrm{AB}$ a & 9,9 А а & $6,5 \mathrm{Ba}$ & $6,1 \mathrm{~B} \mathrm{a}$ & $6,4 \mathrm{Ba}$ & $7,3 \mathrm{AB}$ a & $0,20 \mathrm{ab}$ \\
\hline Médias & 7,2 & 8,2 & 8,1 & 6,4 & 6,4 & 6,7 & 0,20 \\
\hline CV\% & & & & 0,2 & & & 17,8 \\
\hline
\end{tabular}

Médias de épocas seguidas das mesmas letras, maiúsculas na linha e minúsculas na coluna, não diferem entre si, pelo teste de Tukey (p < 0,05).

TABELA 3 - Quantidade (g) de Zn exportada por tonelada de frutos frescos de progênies de aceroleira em diferentes épocas do ano (meses do ano agrícola de 1999/2000). Pacajus-CE, 2000.

\begin{tabular}{|c|c|c|c|c|c|c|}
\hline \multirow{3}{*}{$\begin{array}{l}\text { Progênies } \\
\text { P-52 }\end{array}$} & \multicolumn{6}{|c|}{$\mathrm{Zn}\left(\mathrm{g} \mathrm{t}^{-1}\right)$} \\
\hline & Dezembro & Fevereiro & Abril & Junho & Agosto & Outubro \\
\hline & $13,5 \mathrm{Aa}$ & $16,0 \quad \mathrm{Aa}$ & 17,4 A a & 13,0 A a & $18,2 \mathrm{Aa}$ & $21,3 \mathrm{Ab}$ \\
\hline $\mathrm{P}-78$ & 13,3 A a & 15,4 A a & 14,1 A a & $11,6 \mathrm{Aa}$ & $13,2 \mathrm{Aa}$ & $15,9 \mathrm{Ab}$ \\
\hline$P-93$ & $17,7 \quad \mathrm{Aa}$ & $20,5 \mathrm{Aa}$ & $16,4 \mathrm{Aa}$ & $9,6 \mathrm{Aa}$ & $16,7 \mathrm{Aa}$ & $17,5 \mathrm{Ab}$ \\
\hline P-97 & $18,5 \mathrm{~B} \mathrm{a}$ & $19,3 \quad \mathrm{~B} \mathrm{a}$ & $16,6 \mathrm{~B} \mathrm{a}$ & $10,9 \mathrm{~B} \mathrm{a}$ & $15,3 \quad \mathrm{~B} \mathrm{a}$ & $36,0 \mathrm{Aa}$ \\
\hline Médias & 15,6 & 18,4 & 15,4 & 11,5 & 14,4 & 19,6 \\
\hline
\end{tabular}

Médias de épocas seguidas das mesmas letras, maiúsculas na linha e minúsculas na coluna, não diferem entre si, pelo teste de Tukey (p < 0,05). 


\section{CONCLUSÕES}

1 - A maior exportação de nutrientes por tonelada de frutos frescos ocorreu nos meses de maior precipitação (fevereiro e abril).

2 - De forma geral, as progênies estudadas não diferiram entre si quanto à exportação de macronutrientes por tonelada de frutos frescos.

3 - As progênies P-52, P- 93 e P-97 exportaram maior quantidade de $\mathrm{Cu}$ e $\mathrm{Zn}$.

4 - A seqüência de exportação de nutrientes por tonelada de frutos frescos de aceroleira foi: $\mathrm{K}>\mathrm{N}>\mathrm{P}>\mathrm{Mg}>\mathrm{Ca}>\mathrm{S}>\mathrm{Fe}>\mathrm{Zn}>\mathrm{Mn}>\mathrm{Cu}$.

\section{REFERENCIAS}

ALVES, R.E.; SILVA, A.Q.; SILVA, H.; MUSSER, R.S.; MALAVOLTA, E. Contribuição ao estudo da cultura da acerola. II - Teores de nutrientes em plantas antes da frutificação e em seus frutos por ocasião da colheita. Agropecuária Técnica, Areia, v.11, n.1/2, p.64-75, 1990 .

ANDRADE, L.R.M. Corretivos e fertilizantes para culturas perenes e semiperenes. In: SOUSA, D. M. G.; LOBATO, R. (Ed.). Cerrado: correção do solo e adubação. 2. ed. Brasília: Embrapa Informação Tecnológica, 2004. p. 317-366.

BLANCHAR, R.W.; REHM, G.; CALDWELL, A. C. Sulfur in plant material by digestion with nitric and perchloric acid. Proceedings of the Soil Science Society of America, Madison, v.29, p.71-72, 1963.

BRAGA, J.M.; DEFELIPO, B.V. Determinação espectrofotométrica de Pem extratos de solo e material vegetal. Revista Ceres, Viçosa, v.21, n.113, p.73-85, 1974.
BRAGASOBRINHO, R.; BANDEIRA, C.T.; ALVES, R.E. Acerola: a cereja tropical. Fortaleza: Embrapa Agroindústria Tropical, 2001. fôlder

BRUNINI, M.A.; MACEDO, N.B.; COELHO, C. V.; SIQUEIRA, G.F. Caracterização física e química de acerolas provenientes de diferentes regiões de cultivo. Revista Brasileira de Fruticultura, Jaboticabal, v.26, n. 3, p. 486-489, 2004.

CORDEIRO, E.R. Seleção de progênies de polinização livres e estimativas de parâmetros genéticos em acerola (Malpighia emarginata D.C.). 2000. Dissertação (Mestrado em Fitotecnia) Universidade Federal do Ceará, Fortaleza, 2000.

CUNHA, R.C.S.; SILVAJÚNIOR, J.P.; CONCEIÇÃOJÚNIOR,A.C.; SILVA, A.Q.H. Teores de nitrogênio, fósforo e potássio em função da idade e época do ano na cultura da acerola (Malpighia glaba. L.). Revista Brasileira de Fisiologia Vegetal, Brasília, v.5, n.1, p.73, 1993.

FREIRE, J.L.O. Acerola (Malpighia sp): concentrações de NPK em plantas e caracterização físico - química de frutos em pomares de diferentes regiões da Paraíba. 1995. Dissertação (Mestrado em Fitotecnia) - Universidade Federal da Paraíba, Areia, 1995.

FREIRE, L. O. F; LIMA, A. N; SANTOS, F.G.B.; MARINUS, J.V.M.L.; FREITAS, H.E.S.C. Teores de nutrientes na área foliar de plantas em fase de produção e exportação de nutrientes de frutos de acerola em pomares do Estado da Paraíba. Engenharia Ambiental, Espírito Santo do Pinhal, v.4, n.2, p. 79-91, 2007.

GONZAGA NETO, L.; MATTUZ, B.H.; SANTOS, C.A.F. Caracterização agronômica de clones de aceroleira (Malpighia spp) na região do submédio São Francisco. Revista Brasileira de Fruticultura, Jaboticabal, v.21, n.2, p. 110-115 , 1999 